\title{
Research Overview of Big Data in the Field of Equipment Support
}

\author{
Jinli Che ${ }^{a}$, Liwei Tang, Shijie Deng \\ Department of Artillery Engineering, Ordnance Engineering College, Shijiazhuang 050003, China. \\ a17603200861@163.com
}

Keywords: military, equipment support, big data, data analysis.

\begin{abstract}
The arrival of the era of big data has a profound impact on the development of the society and world economy, changing people's work, life and way of thinking. With the continuous maturity of big data technology, its application in the military field will become inevitable. This paper mainly expounds the research status of big data application in the field of military equipment support, and finally analyzes its challenges.
\end{abstract}

\section{Introduction}

With the continuous development of Internet technology, today's society has entered a big data era of explosive growth of data. Since 2009 big data concepts and big data technology began to gradually draw attention. That people often said the explosion of information and massive data in the past is not enough to describe this new phenomenon. At the National People's Congress and Chinese People's Political Consultative Conference in 2015, the proposals of big data burst as the blowout. After this, China's State Council officially raised big data to the height of the country's core strategy. Its significance lied not only in mastering vast amounts of data, but also in using effective means to extract the information and value hidden in the data.

At present, the application of big data is very common and its range is very wide, such as telecommunications, retail, online shopping, dating, medical treatment, transportation, security enforcement, meteorological environment monitoring, and government management and so on. Many industries are in the use of big data technology to promote development and enhance competitiveness. It can be said that big data has infiltrated all aspects of our lives, perhaps one of your careless life behaviors involves big data technology.

However, it is not difficult to find the information of big data applications in the field of military is very little. This is of course due to security factors, but you can also see the lag behind of big data applications in the military field from the other side. According to the information currently available, the development of big data in American has been at the forefront of the world. The Obama administration has risen the big data strategy as the highest national policy. It thinks big data is the new oil of the future. The possession and control of data will be another national core capability beyond land rights, sea power and air rights. The United States Department of Defense plans to invest \$250 million per year to carry out a series of research projects in each military department. The aim is to use massive amounts of data in an innovative way and strengthen the ability to make decisions in big data by combining perception and cognition. From the research of the United States military on big data, it can be seen that the study of big data applications in the military field is the trend of the times. In China's military informatization construction, especially in the field of equipment support, big data will also have a revolutionary impact.

\section{Big Data and Equipment Support}

\subsection{The Put Forward of Big Data.}

In 1989, Howard Dresner of the Gartner Group first proposed the term business intelligence [1]. Business intelligence was usually understood as a tool for transforming existing data into knowledge and helping companies make informed business decisions. The main goal was to transform the 
information that the enterprises had mastered into competitive advantages, and to improve the decision-making ability, decision-making efficiency and accuracy of decision-making. In order to transform the data into knowledge, it was necessary to use data warehouse, online analytical processing (OLAP) tools and data mining technology [2]. With the development of the Internet, more and more data are collected and the structure of data is more and more complex. General data mining technology can no longer meet the needs of large enterprises, which makes enterprises begin to consciously seek new ways to solve large amounts of data that cannot be stored and processed. Thus, a new term, big data, is born in the IT world.

There is no clear definition of the concept of big data at the moment. A number of enterprises, institutions and data scientists have already described the big data. Although the description is not the same, there is a general consensus that the key to big data is to obtain information quickly in a wide variety of large amounts of data. The Wikipedia defines the big data as: The amount of data involved is so large that it cannot be captured, managed, processed, and collated to become a more informative source of business decisions through the current mainstream software tools. The Internet Data Center (IDC) defines the big data as: A new generation of architectures and technologies designed to gain more value from high-frequency data, large-capacity data, different structures and types of data. The information expert XU Zi-pei said in his book big data [3]: Big data not only refers to the large capacity. Its greater significance is to discover new knowledge, create new value, bring big knowledge, big science and technology, big profit and great development through the massive data exchange, integration and analysis.

From data to big data, it is not only the difference in quantity, but also the improvement of data quality. Traditional methods of data processing include data mining, data warehouse, OLAP and so on. However, in the era of big data, data is more than just content to be analyzed. The more important is that people need special ideas and methods to collect, sort out and analyze data from a large number of messy and complex data to predict and plan social life and support decision-making in the commercial field. The well-known database expert, Turing Award winner Dr. Jim Gray summed up that it has gone through three paradigms: empirical, theoretical and computational in the history of human science. Nevertheless, with the increasing amount of data and the complexity of data structure, these three paradigms are not enough to be used in the new research field. So Dr. Gray Jim proposed the new scientific fourth paradigm, data exploration, to guide and update scientific research in the field [4].

\subsection{The Features of Big Data.}

Big data has the $4 V$ features of volume, variety, velocity and value [5]. (1) Volume: During the Afghanistan war, in order to combat a small number of terrorists the U.S. Army's full range of intelligence reconnaissance surveillance system deployed in space, air, and ground generates 53TB data within 24 hours. In the day-to-day management of our military aircraft, only one flying regiment will produce hundreds of millions of flight parameter records every day. The collection, storage and distribution of these data will be far beyond the management capabilities of traditional management techniques. (2) Variety: The data produced in the information-based war are diverse, including structured data (such as database data, structured text data), semi-structured data, unstructured data and other types of data (such as web logs, geographic location, pictures, audio, video, etc.). For different data types, their processing and analysis methods are also very different. (3) Velocity: In order to effectively deal with massive data and many types of data, we must design and develop efficient data collection and processing system. A new generation of big data system, for example, is being developed by the US military. It can understand and explain the real world through the speed and accuracy of the computer and the agility of human beings to assist commanders and analysts to understand the vast amounts of data collected by sensors at a rate of 100 times faster than today. (4) Value: Big data contains a lot of potential value. In modern warfare, the combat forces use a variety of reconnaissance equipment to collect and process battlefield data. These data reflect the entire weaponry and battlefield environment, thus controlling the progress of the war. 


\subsection{The Concept of Equipment Support.}

The equipment support, the abbreviation of military equipment support, is to meet the needs of the troops carrying out various tasks. It is a general term of a series of guarantee measures adopted for equipment and the corresponding activities [6]. Equipment support is essentially a kind of service activity. Its significance lies in its effective support to assist the troops in accomplishing their combat tasks so as to achieve the original purpose and value of equipment support. Equipment support plays a key role in the military activities of the whole army. Whether the equipment support is timely and powerful can directly affect the process and ending of the whole warfare. Therefore, the military benefits of big data applications in the field of equipment support will be self-evident.

\subsection{The Data of Equipment Support.}

The data of equipment support refers to all data and information closely related to equipment support activities. General equipment support data including the geographical environment, meteorological phenomena, national conditions, basic tasks, Enemy and our intelligence, etc. And the equipment support data in narrow sense refers to the weaponry type, performance, quantity, quality and usage, etc. At present, our military equipment department has developed and used the relevant data management system. However, compared with other advanced countries, our army is still in a backward state in the field of equipment support, command and control construction. This is mainly manifested in two aspects:

(1) Data complexity: The informatization construction of our army has entered a new stage of accelerated development, and the upgrading of weaponry has been accelerated. This leads to the coexistence of multiple generations of weaponry and a great deal of complex data in the process of equipment support. What's more, because of the research, production, allocation, use and support of weapon equipment belonging to different units and personnel, the equipment data is prone to accumulate, lose and repeat.

(2) Data silos: With the development of information technology and network technology, the data information system of our army is developing steadily. However, due to the lack of reasonable and effective management and control methods, the equipment support agencies in each department operate separately and lack the necessary coordination and communication. This leads to a growing gap between departments, and gradually formed a data chimney. Therefore, the upper equipment support departments cannot pinpoint the equipment support information. So far, it is difficult to break the data chimney between departments, which leads to the data silos of equipment support data.

\subsection{The Superiority of Applying Big Data Technology into Equipment Support.}

Big data technology is an effective combination of modern information technology, such as network technology, artificial intelligence and database technology. Big data technology can be used to analyze the relevance of data under the multi system conditions, such as geographic information system, meteorological system and command system. It can find out the relevance of data, extract valuable information, provide data support for decision makers, and also directly implement comprehensive analysis by big data decision system, and give decision-making scheme for decision makers. The significance of big data to equipment support decision lies in: (1) Predictive analysis: That is to predict and judge the decision-making activities, and then make a simulation analysis of the activities of the equipment support implementation stage, so as to provide better decision-making reference for decision makers. (2) Battlefield perception: That is to say that big data can be related to the battlefield and all equipment support information tracking. Therefore, we can real-time grasp the latest data changes, always grasp the needs of battlefield equipment support and help decision makers make accurate equipment support plan to support the front battle. (3) Postwar feedback: Big data technology has real-time monitoring capability. So that we can understand the implementation of equipment support decision-making and the implementation of equipment support activities in a timely manner, and provide reference for the decision-making of equipment support in the following tasks. The arrival of big data era has changed the situation of small data era, relying on empirical analysis to judge things. Instead, innovative models of using big data offer new ideas and ways for decision makers. 


\section{Research Status at Home and Abroad}

\subsection{Research Status Abroad.}

Informatization is a major trend in the development of national economy and weaponry, as well as the inevitable trend in the development of equipment support technology. Western developed countries began to apply big data technology in military equipment field in 1980s. At that time, the United States Air Force laboratory set up the database of aviation system cost in the research and development of combat aircraft, and estimated the life cycle cost of the system through historical data. After that, with the continuous development of computer technology, the United States, Britain and France, gradually applied big data technology to all fields of equipment development, especially in the engineering practice of equipment support [7].It is the inevitable course to use today's rapid development of digital communications, network transmission and other information technology to improve equipment support management. The input, analysis, routine planning arrangements of equipment support information are completed by the computer. Instructions or data are sent electronically and controlled by the program. The application of information technology to realize the intelligence of equipment support can greatly improve the efficiency of equipment maintenance support. The US military is using its technical advantages in the information field to improve its maintenance support technology so as to strengthen maintenance data management and improve maintenance support efficiency.

\subsection{Research Status at Home.}

Although the work about weaponry, especially equipment support, has been carried out for more than 50 years, the work in the field of big data is still in its infancy. At present, big data technology has attracted some attention, arms and equipment sector also began to actively explore and try in the field of big data. With the continuous improvement of military equipment informatization construction, big data technology will be more widely used.

The researchers carried out a great deal of research on the possibility analysis and development strategy of the big data in the equipment support system, providing reference for the application of big data technology in the field of equipment support. CAO Hui-zhi, LI Pei et al. [8] pointed out that realizing the autonomy of core technology of big data development platform is the only way for the development of equipment support informatization, and put forward an innovative idea about using big data processing technology to deal with Advanced Persistent Thread (APT) attack. XIE Feng, SUN Jiang-sheng et al. [9] started from the analysis of the diversity and heterogeneity of equipment support data sources. They proposed the architecture of data warehouse for equipment support and analyzed the functional requirements of the system. And they constructed the functional requirements model of equipment support data warehouse from the macroscopic angle, which laid the foundation for the efficient management and utilization of the equipment support data in the future. JIA Ye et al. [10] proposed and constructed the system frame, system module and system structure of equipment support decision-making system according to the technical characteristics of data warehouse. It solved the problem of redundant data and poor useful information in the decision-making support system of traditional equipment support.

\section{Challenges and Solutions}

Big data technology is now in its infancy, mainly facing the broad heterogeneity of data, incomplete data, real-time data processing, lack of prior knowledge, privacy issues and other challenges. The problems encountered in the application of big data in equipment support are basically the same as those encountered in big data technology. Therefore, the application of big data in the equipment support is mainly facing the following problems.

\subsection{Security and Privacy Issues.}

With the development of big data, the sources and application fields of equipment support data are more and more extensive. The development, production, use and support of weaponry will produce a large amount of data. Data experts can easily dig out the important information of weapons performance indicators through relevant data analysis. If the information is used properly, it can help 
the relevant experts to understand the needs and habits of the army, facilitate the adjustment of the corresponding equipment support plan, and improve the efficiency of support. But if these important messages are stolen by undesirable elements, then there will be important national security issues.

In order to solve the problem of data privacy in the era of big data, academia and industry have put forward their own solutions. Lindell et al. [11] put forward the concept of privacy preserving data mining for privacy protection. Sweeney et al. [12] presents a k- anonymous method for location-based service security problems. It is to combine yourself with k-1 users to form a data set, thus obscuring your location concept. Differential privacy protection technology may be a powerful weapon to solve the privacy problem of big data. Dwork et al. [13] proposed a new differential privacy method in 2006. Roy et al. [14] put forward a privacy protection system, Airavat, in 2010. They integrate centralized information flow control and differential privacy protection technology into the data generation and computing phase of cloud computing to prevent data privacy leakage during the MapReduce computing process.

In addition, in the era of big data, equipment support data updates and changes faster, but the general data privacy protection technologies are mostly based on static data protection, which brings new challenges to privacy protection. How to realize the data privacy protection under complex changing conditions is one of the key directions in the future research of equipment support.

\subsection{The Heterogeneity of Equipment Support Data.}

The sources of equipment support data are different. Some data from the support data provided by the army, some from the support plan of research institutes, and some from the maintenance data of maintenance plants. This leads to a change in the data type from structured data to the integration of structured, semi-structured and unstructured data. How to store and analyze these heterogeneous data in a unified way will be a problem worthy of further study.

\subsection{The Real-time Performance of Equipment Support Data.}

With the passage of time, the value of knowledge contained in data is often attenuated, so real-time performance is also a question that must be considered in the process of big data analysis for equipment support. Especially in the analysis of data relating to weather and environmental conditions, the untimely analysis of big data may lead to the occurrence of equipment support accidents. Because of the enormous amount of data, whether you can complete the assigned work within the limited time is a way to measure big data analysis. One way to solve this problem is to combine data processing with stream processing and batch processing.

\subsection{Data Mining of Equipment Support Data.}

The heterogeneity of equipment support data leads to various types of equipment support data. And because the data set is too large, the traditional algorithms such as data mining and machine learning are no longer suitable for mining big data of equipment support. Because existing algorithms are often used for small data sets, for large data sets, it can lead to inefficient or even not being used at all. One of the important characteristics of big data application for equipment support is real-time, and the accuracy rate of the algorithm is no longer the main index. We need to strike a balance between real-time and accuracy in the process of processing. In order to solve this problem, we can improve the algorithm of small data processing, so that it can take into account both accuracy and real-time. This will also be the focus of scientific research in the next period of time.

\section{Conclusion}

The arrival of the big data era is both an opportunity and a challenge for the field of military equipment support. Only when we grasp the opportunity, take the initiative to meet the challenge and master the development trend of big data technology, can we help promote the rapid development of equipment support construction. At present, the application of big data for the work of military equipment support has achieved initial success, but the military application of big data is still in the initial stage. There will still be a long way to go. Only by constant research and continuous exploration can we really give full play to the great value of big data in equipment support. 


\section{References}

[1]. YU Chang-hui, PAN He-ping. Business Intelligence and Its Key Technology [J]. Application Research of Computers.19 (2002)9,14-16.

[2]. XIONG Zhong-yang. Research on Parallel Data Mining and Application for Business Intelligence [D].Chongqing University,2004.

[3]. XU Zi-pei. Big Data[M].Guangxi Normal University Press,2012,54-58.

[4]. Tony Hey,Stewart Tansley,Kristin Tolle.The Fourth Paradigm: Data-Intensive Scientific Discovery[M]. Science Press, 2012,15-19.

[5]. ZHANG Wen-hao, WANG Xue-zhi. Analysis of The Necessity of Big Data Application in Equipment Support Decision [J].China Management Informationization.18 (2015)9,70-71.

[6]. LI Zhi-shun, WU Ming-xi. Science of Military Equipment Support [M].Military Science Publishing House, 2009,8.

[7]. WANG Xu-zhi. The development trend of foreign armed[C].Chinese Shipbuilding Engineering Society Shiprepairing Technology Annual Meeting of Academic Committee of 2003.

[8]. CAO Hui-zhi, LI Pei, LIU Jun-jie, et al. Research on the construction and development of equipment support under the background of big data[J]. China Management Informationization, 17(2014)17,52-54.

[9]. XIE Feng, SUN Jiang-sheng, DAI Dong-sheng, et al. Research on Model of Equipment Data Management System Based on Data Warehouse [J]. Value Engineering,26(2013),192-195.

[10]. JIA Ye, GUO Qi-sheng, HAN Jian, Equipment Support Command and Assistant Decision System Based on Data Warehouse [J]. Value Engineering,33(2014)25,222-224.

[11]. LINDELL Y, PINKAS B. Privacy Preserving Data Mining[J].Journal of Cryptology,15(2002)3,177-206.

[12]. SWEENEY L.K-Anonymity: A Model for Protecting Privacy[J].International Journal of Uncertainty, Fuzziness and Knowledge-Based Systems, 10(2002)5,557-570.

[13]. DWORK C. Differential Privacy[C].Proceedings of the 33rd International Colloquium,ICALP,2006.Venice,2006,4052:1-12.

[14]. ROY I, RAMADAN H E,SETTY $S \mathrm{~T}$ V, et al. Airavat: Security and Privacy for MapReduce[C].Proceedings of the 7th Usenix Symmp. on Networked Systems Design and Implementation. San Jose: USENIX Association.2010,297-312. 